\title{
A study of the experiment teaching of 'the Fundamentals of Computer' based on Computational Thinking
}

\author{
Wu Jin ${ }^{1, a^{*}}$, Wang zhaohui ${ }^{1}$ \\ ${ }^{1}$ School of Computer Science and Technology, Soochow University, SuZhou, China \\ awujin@suda.edu.cn
}

Keywords: The Fundamentals of Computer; Experiment teaching; Computational Thinking; Lnquiry Teaching Model.

\begin{abstract}
Combining with Computational Thinking, the experiment teaching research of 'the Fundamentals of Computer' in universities has become a new direction and goal for the reform and construction of the computer foundation courses. This paper expounds the connotation of Computational Thinking. Centering on cultivating the college students' Computational Thinking ability, the paper expounds how to build the hierarchical experiment teaching contents, introduces the experiment teaching method and evaluation model based on Computational Thinking.
\end{abstract}

\section{Introduction}

Computational Thinking (CT) is an important concept focused by the current international computer educational circles. In 2010, the teaching development strategy alliance for 'the Fundamentals of Computer' of nine universities in China issued a joint statement, which pointed out: 'the Fundamentals of Computer' is an important and indispensable course to cultivate, and it plays an important role for the cultivating of inter-disciplinary talents. So the important position of the Fundamentals of Computer must be correctly understood, and cultivating the college students' Computational Thinking ability should be as the core task for the teaching of 'the Fundamentals of Computer'[1]. Thus it can be seen, the teaching of 'the Fundamentals of Computer' is not only an important part of general education in universities, but also provides an important role to improve the college students' comprehensive quality and cultivate their creative ability.

As an important part of the teaching for 'the Fundamentals of Computer', the experiment teaching plays a decisive role. How to integrate the education concept of Computational Thinking into the experiment teaching of 'the Fundamentals of Computer', how to cultivate the students' computer application abilities based on Computational Thinking, and how to make these abilities as part of the professional skills to solve problems from interdisciplinary in future study and work. All of these problems have been the important subjects which should be considered in the teaching of 'the Fundamentals of Computer'.

\section{What is computational thinking?}

For the first time, the concept of Computational Thinking is put forward by Professor Jeannette M. Wing who is the department head of the computer science department at Carnegie Mellon university in the United States in 2006. And it is widely accepted by the computer education circles. Professor Wing thinks: Computational thinking is a kind of analytical thinking. It shares with mathematical thinking in the general ways in which we might approach solving a problem. It shares with engineering thinking in the general ways in which we might approach designing and evaluating a large, complex system that operates within the constraints of the real world. It shares with scientific thinking in the general ways in which we might approach understanding computability, intelligence, the mind and human behavior [2]. As Professor Wing's point of view, Computational thinking not only belongs to computer scientists. It 
should be the basic skill of each person. We should cultivate the child's analytical ability, which not only includes reading ability, writing ability and arithmetic ability, etc. but also involves Computational thinking ability.

Along with the formation and development of modern science, the understanding for the function and meaning of Computational Thinking is more and more improved. In today's society, Using Computational Thinking to consider and state the problem has become more and more familiar and common. Computational Thinking has become a necessary quality of modern people [3]. Computational Thinking is a basic tool which should be used by everyone in the middle of the $21 \mathrm{st}$ century. When human learn and apply knowledge it will become the basic knowledge and basic skills which just like mathematics and physics. When computing thinking is really integrated into the human activities, each one should grasp it and everywhere can use it as an effective tool to solve problems [4]. Therefore, Computational Thinking has become a basic skill and an indispensable basic way of thinking for modern people.

\section{The experiment teaching of 'the fundamentals of computer' based on computational thinking}

In the reformation for the experiment teaching of 'the Fundamentals of Computer' guided by Computing Thinking ability training", according to the training objectives the common universities should comb and improve the existing curriculum system combined with the features of each university and the application requirements of each major. The training for Computational thinking ability should run through the course system of the experiment teaching of 'the Fundamentals of Computer'. Meanwhile the teachers should carry out the study and research for Computing Thinking, review the course content and teaching methods with Computing Thinking and explore the implementation of the new teaching scheme for specific course.

A. Build the hierarchical experiment teaching contents based on Computational Thinking

Today, carrying out the teaching research and practice based on Computational Thinking is a new issue and a primary task for 'the Fundamentals of Computer' in universities. And it is also the important segment to cultivate the College students' comprehensive quality. We integrate the education concept of Computational Thinking into the experiment teaching of 'the Fundamentals of Computer', and build hierarchical experiment teaching contents, as shown in Fig.1.

\begin{tabular}{|l|}
\hline $\begin{array}{l}\text { Integrated innovative } \\
\text { experiments }\end{array}$ \\
\hline $\begin{array}{l}\text { intensive designing } \\
\text { experiments }\end{array}$ \\
\hline $\begin{array}{l}\text { basic applied } \\
\text { experiments }\end{array}$ \\
\hline
\end{tabular}

Figure. 1 The hierarchical experiment teaching contents

The experiment teaching should be carried out based on major, too. The students' professional knowledge should be brought into the experiment teaching of 'the Fundamentals of Computer' to build a bridge between computer technology and professional learning. So we can design some experiments combine the professional knowledge and computer technology, which can deepen the basic computer teaching and stimulate students' interest in learning.

According to the teaching goal of the experimental course of 'the Fundamentals of Computer', the experiment contents can be divided into three levels: basic applied experiments, intensive designing 
experiments and integrated innovative experiments. For the experiment teaching in each level, we can strengthen students' Computational Thinking ability by multiple perspectives and multiple means.

Firstly, Computational Thinking should be fully embodied in basic applied experiments. Generally these experiments are some verification experiments, which can help some students with poor basis to verify their basic knowledge points and grasp basic skills by these specific verification operations. We often use many teaching methods, such as 'Inquiry Teaching Model', 'Task-Driven Teaching Model', etc. By clearing the experiment requirements, we can ask students some questions, guide them to think seriously about these questions and find out various solutions, then solve these questions with correct method and get correct experiment result by computer. Besides, we can add some thinking contents to existing experiment contents based on each knowledge point, which can make students comprehend the leading role of Computational Thinking in the experiment teaching of 'the Fundamentals of Computer'.

Secondly, intensive designing experiments usually cover some knowledge points at a medium level of difficulty and put emphasis on flexibly applying these knowledge points to cultivate students' computer application ability. These experiments are extended and suitable for students in different majors and levels. In fact, doing this kind of experiment is a self-learning process for the student. Student should complete the experiment independently on the basis of the basic applied experiments and knowledge points he had learned. By intensive designing experiments, students can learn the method to build the commonly used mathematical model with abstract thinking way. So they can understand how to deal with the problems with Computational Thinking (For example: Put forward specific problems $->$ Construct models $->$ Get the results) [5].

Thirdly, integrated innovative experiments are mainly aimed at the difficulty and innovation in the teaching. They lay emphasis on cultivating students' innovation ability. These experiments are usually some exploratory comprehensive experiments with great difficulty. They can be completed by several students in cooperation. Integrated innovative experiments also pay attention to the students' ability to apply the comprehensive knowledge, which can maximize the students' initiative and creativity. The students' Computational Thinking and capacity can be best showed in these experiments. Therefore, when designing the experiment contents, we should not only think about the actual demand of each major to the computer technology, but also consider how to cultivate the students' Computational Thinking ability. By finishing these experiments, the students can more actively explore and deeply study. Then they can expand their innovation consciousness, enhance their handling ability and improve their innovation ability.

B. Implement 'Inquiry Teaching Model' experiment teaching method based on Computational Thinking

As mentioned above, the experiment teaching of 'the Fundamentals of Computer' should lay emphasis on how to cultivate the students' Computational Thinking ability. For this purpose, new teaching contents should be reformed, and appropriate experiment teaching methods should also be explored.

'Inquiry Teaching Model' is an effective teaching method that students self-learn and inquire the knowledge points of present teaching contents with the help of their teachers, and collaborate with the other students to solve problems. This teaching model has the characteristics 'autonomy, inquiry and cooperation'. 'Inquiry Teaching Model' can be used in the experiment teaching of 'the Fundamentals of Computer'. Meanwhile, by using Computational Thinking method, we can carry out Inquiry Teaching by three basic steps (Ask questions, Inquiry questions and Get solutions) for the academic knowledge in classroom teaching.

As shown in Fig.2, the core of 'Inquiry Teaching Model' is 'Ask questions', which should stick to the requirements of teaching goals. Based on these questions, every knowledge points should be included in the process of solving questions. Students can deepen their understanding for the knowledge points by using Computational Thinking to inquire questions and solve questions. 'Inquiry 
questions' can be divided into the students' independent inquiry and team cooperation inquiry. By independent inquiry, students can acquire sufficient self-understanding to the new knowledge and find their own shortcomings. Moreover, by team cooperation inquiry, some puzzles occurred in independent inquiry or other questions can be solved. Team learning can also deepen students' understanding for the knowledge points. After get solutions for the questions, teachers can guide students to summarize them and sort out the solving strategies for relevant questions.

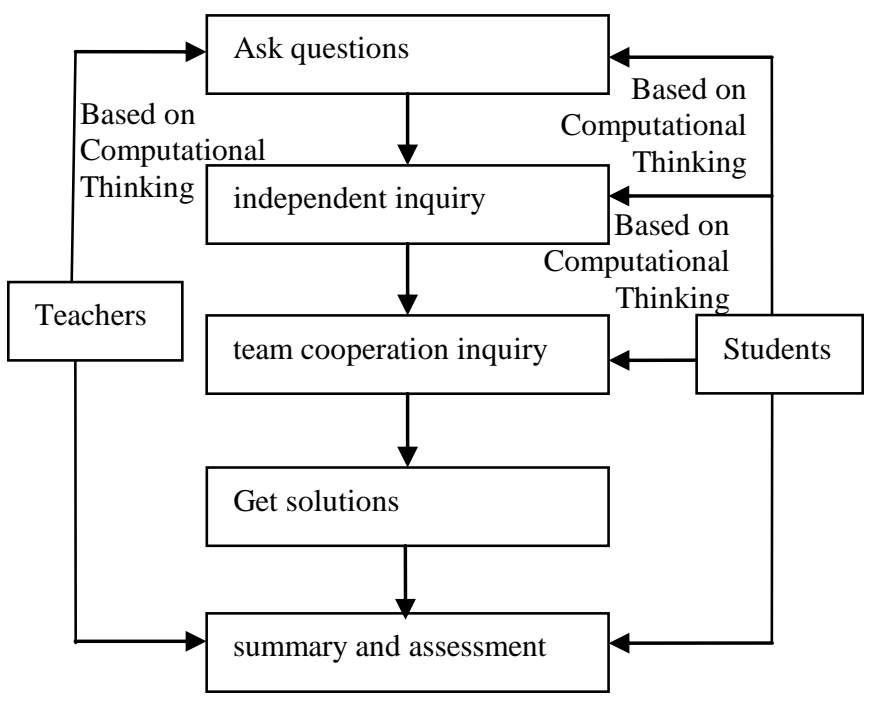

Figure. 2 Inquiry Teaching Model

For example, when teaching the knowledge point 'Classification statistics' in 'Excel 2003', we can let students to think how to calculate the average value of the teachers' basic salary and bonus in different professional Titles. After the students put forward some solutions, we can introduce the knowledge point 'Classification statistics' in 'Excel 2003', and teach students how to calculate the average value by 'Classification statistics'. Then we further let students to think how to calculate the maximum value of the teachers' basic salary and bonus in different professional Titles. So the students can continue to inquire the question. This kind of learning process (Ask questions->Inquiry questions-> Get solutions) can cultivate the students' exploring spirit and stimulate their interest in learning.

C. Design procedural examination evaluation model based on Computational Thinking

The traditional evaluation model of the experiment teaching of 'the Fundamentals of Computer' mainly contains the final practice examination, the regular attendance grade and the experiment results of a week. This kind of exam-oriented education model is relatively simple, which can't test the students' learning efficiency and reflect the students' practical ability in all directions. So it is bad for the cultivation of innovative talents. Therefore, we set out a new evaluation criteria in our reformation of experiment teaching. This new evaluation model uses layered scoring mechanism based on Computational Thinking. Firstly, teacher should check the experiment result in every week and score it. Each score can be calculated into the final overall grade. On this basis, teacher should add some big projects to exercise and cultivate the students' Computational Thinking ability better when the experiment teaching has finished one or several units. These big projects should fully embody Computational Thinking. Students can well learn the processing method with Computational Thinking by independently or collaboratively completing these big projects. Meanwhile, the practice examination is no longer confined to the final practice examination. Procedural examination evaluation model can be used. Throughout the semester the teacher examines the students in stages by organizing unit examination for 3 5 times. Each examination score should be calculated into the final overall grade to overall evaluate students' mastery condition for the knowledge points in every unit. 


\section{The teaching effects}

We applied the hierarchical experiment teaching of 'the Fundamentals of Computer' based on Computational Thinking in students of year 2014 in our university, which achieved good teaching effects. We have done some investigations on these students for the teaching effects at the end of the semester. One investigation is about the students' feedback for the course, which is shown as table 1.

Besides, we have made an investigation for the teaching situation of our experiment teaching course on the students of year 2013 and year 2014. All of these students are involvedin 18 classes which are taught by us in recent two years. And the experiment teaching of year 2013 has not applied the hierarchical teaching based on Computational Thinking. Altogether 1463 students (among which students of year 2013835 and year 2014628 ) accepted this investigation. We mainly compared their examination scores. As shown in Fig.3.

Table 1 Students' feedback for the hierarchical teaching based on computational thinking at the end of the semester

\begin{tabular}{|l|l|l|l|}
\hline \multicolumn{1}{|c|}{ question } & Yes & a little & No \\
\hline Is Hierarchical teaching right for you? & $90.8 \%$ & $7.9 \%$ & $1.3 \%$ \\
\hline $\begin{array}{l}\text { Has your Computational Thinking } \\
\text { ability been improved? }\end{array}$ & $88.9 \%$ & $9.2 \%$ & $1.9 \%$ \\
\hline $\begin{array}{l}\text { Has this teaching mode improved your } \\
\text { computer abilities? }\end{array}$ & $93.1 \%$ & $5.6 \%$ & $1.3 \%$ \\
\hline $\begin{array}{l}\text { Do you like this kind of teaching mode } \\
\text { for experiment course? }\end{array}$ & $98.5 \%$ & $0.9 \%$ & $0.6 \%$ \\
\hline
\end{tabular}

From Fig.3, the percent of excellence in 2013 is 35.5\%. In 2014, we applied the hierarchical experiment teaching of 'the Fundamentals of Computer' based on Computational Thinking. The percent of excellence is $59.3 \%$. It is obviously that the percent of excellence is improved greatly. Meanwhile the percent of pass and fail are reduced apparently. All of these shows that the hierarchical experiment teaching of 'the Fundamentals of Computer' based on Computational Thinking is very effective.

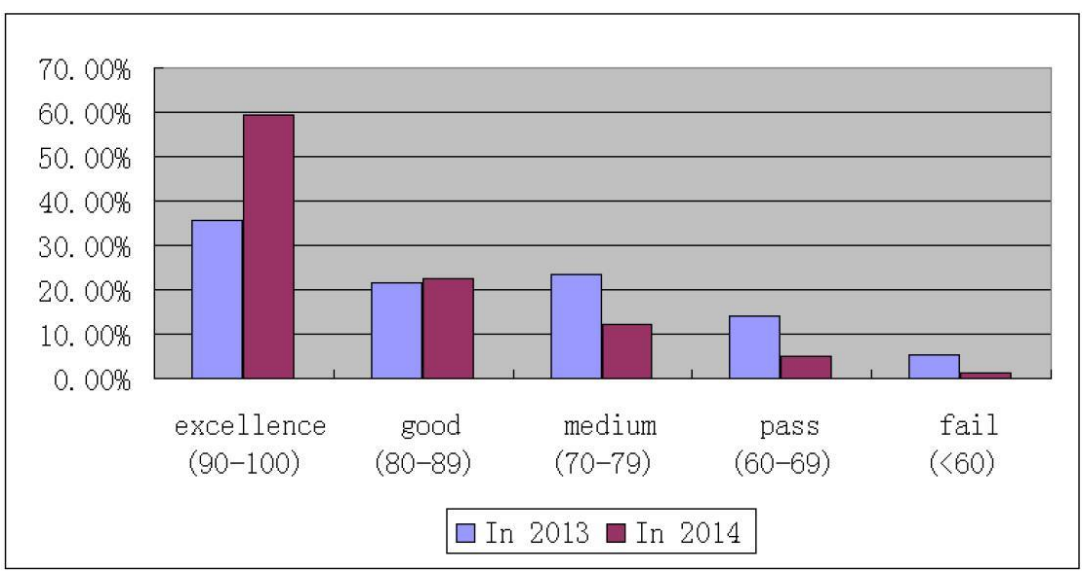

Figure. 3 Examination comparison in 2013 and 2014

\section{Conclusion}

The teaching of 'the Fundamentals of Computer' not only teaches the students' computer application skill, but also cultivates them to grasp the common method of thinking and solving computer science problems, then promotes the improvement of the students' computer ability, innovation ability and Computational Thinking ability. As an important part of the teaching of 'the Fundamentals of Computer', the performance of the experiment teaching will be able to directly affect the cultivation of the students' innovative thinking ability and ability to analyze and solve problems by computer. How to develop their own Computational Thinking ability and apply it in the teaching of 'the Fundamentals 
of Computer' to cultivate more excellent talents needed by the society, which is still a subject worth exploring.

\section{Acknowledgements}

The research work was supported by the open experiment teaching project of the national experimental teaching demonstration center of computer and information technology in Soochow University.

\section{References}

[1] He Qingming, Lu hanquan, Feng boqin. The core task of The teaching of 'the Fundamentals of Computer' is the cultivation of Computational Thinking ability [J]. China University Teaching, 2010(9).

[2] Wing J M. Computational Thinking [J]. Communication of theACM, 2006, 49( 3) : 33-35.

[3] Li lian. Computational Thinking-- Concepts and challenges [J]. China University Teaching, 2012(1):7-12.

[4] Chen guoliang, Dong rongsheng. Computational Thinking and the education of 'the Fundamentals of Computer' [J]. China University Teaching, 2011(1): 7-11.

[5] Zhu yong, Yang hongwei, Song xiaoqiang. The training way of Computational Thinking in the teaching of 'the Fundamentals of Computer' [J] . computer education, 2013(5):35-38.

[6] Wing, J.M. Computational thinking and thinking about computing [J]. Philosophical Transactions of the Royal Society London, Series A, 2008, 366(1881):3717-25.

[7] Astrachan, O; Hambrusch, S.; Peckham, J.; Settle, A. The present and future of computational thinking [J]. SIGCSE Bulletin, 2009, 41(1): 549-50.

[8] Philip, M. A pragmatic approach to develop computational thinking skills in novices in computing education [J]. 2013 IEEE International Conference in MOOC, Innovation and Technology in Education (MITE), 2013:199-204.

[9] $\mathrm{Hu}$, Chenglie. Computational thinking - What it might mean and what we might do about it [J]. ITiCSE'11 - Proceedings of the 16th Annual Conference on Innovation and Technology in Computer Science, 2011:223-227.

[10] Kuo-Chuan Yeh; Ying Xie; Fengfeng Ke. Teaching computational thinking to non-computing majors using spreadsheet functions[J]. 41st ASEE/IEEE Frontiers in Education Conference (FIE 2011), 2011, p F3J (5 pp.). 